Article

\title{
Diversity Patterns of Bermuda Grass along Latitudinal Gradients at Different Temperatures in Southeastern China
}

\author{
Jing-Xue Zhang ${ }^{1}$, Ming-Hui Chen ${ }^{1}$, Lu Gan ${ }^{1}$, Chuan-Jie Zhang ${ }^{1}$, Yu Shen ${ }^{1}$, Jin Qian ${ }^{1}$, \\ Meng-Li Han ${ }^{1}$, Yu-Xia Guo ${ }^{2, *}$ and Xue-Bing Yan ${ }^{1, *}$ \\ 1 College of Animal Science and Technology, Yangzhou University, Yangzhou 225000, China; \\ dx120190128@yzu.edu.cn (J.-X.Z.); dx120170094@yzu.edu.cn (M.-H.C.); ganlu2019@yzu.edu.cn (L.G.); \\ chuanjiezhang@yzu.edu.cn (C.-J.Z.); mz120170925@yzu.edu.cn (Y.S.); mz120170924@yzu.edu.cn (J.Q.); \\ MX120190685@yzu.edu.cn (M.-L.H.) \\ 2 College of Animal and Veterinary Science, Henan Agricultural University, Zhengzhou 450002, China \\ * Correspondence: guoyuxia@henau.edu.cn (Y.-X.G.); 006817@yzu.edu.cn (X.-B.Y.); \\ Tel./Fax: +86-371-63558180 (X.-B.Y.)
}

Received: 12 November 2020; Accepted: 10 December 2020; Published: 15 December 2020

\begin{abstract}
Cynodon dactylon (L.) Pers. (common Bermuda grass) has a limited capacity to grow at low temperatures, which limits its geographical range. Exploring its evolutionary relationship across different environmental gradients is necessary to understand the effects of temperature change on the genetics of common Bermuda grass. In this study, high-throughput transcriptome sequencing was performed on 137 samples of $C$. dactylon from 16 latitudinal gradients to explore the differential molecular markers and analyze genetic diversity and structure along latitudinal gradients at different temperatures. We primarily sampled more high-quality single nucleotide polymorphisms (SNPs) from populations at lower and middle latitudes. Greater intraspecific genetic variation at each level of temperature treatment could be due to factors such as wind pollination and asexual breeding. Populations of $C$. dactylon at high latitudes differed from populations at middle and low latitudes, which was supported by a principal component analysis (PCA) and genetic structure analysis, performed at different temperatures. We observed more genetic variation for low-latitude populations at $5{ }^{\circ} \mathrm{C}$, according to an analysis of three phylogenetic trees at different temperature levels, suggesting that low temperatures affected samples with low cold resistance. Based on the results of phylogenetic analysis, we found that samples from high latitudes evolved earlier than most samples at low latitudes. The results provide a comprehensive understanding of the evolutionary phenomenon of landscape genetics, laying the groundwork for future structural and comparative genomic studies of C. dactylon.
\end{abstract}

Keywords: Cynodon; evolution; latitude; SNP; temperature

\section{Introduction}

A major focus of evolutionary biology is understanding how genetic variation drives local adaptions across populations spanning wide geographical and environmental gradients. While genetic mutations and genetic drift tend to induce divergence in plant populations, natural selection produces similar adaptations to similar environments. It is important to characterize relative genotypic differences across different locations based on multiple environmental tests [1]. Natural genetic differences related to the drought stress tolerance of plants, such as Festuca arundinacea Schreb and Lolium perenne L., have been studied [2,3]. Adaptations to this kind of stress have important implications for plant growth and adaptation to climate change $[4,5]$. C. dactylon is a warm-season turfgrass primarily ranging from latitudes of $45^{\circ} \mathrm{N}$ to $45^{\circ} \mathrm{S}$. It is widely used for lawns, parks, and sports fields [6]. C. dactylon is an 
ideal species for studying genetic and genomic evolution because of its extraordinary morphological diversity and ecological adaptations. Additional studies are needed to better understand the ability of populations to adapt to global climatic changes that are altering local environmental conditions [7]. Temperature has a major effect on the geographic distribution of plants [8]. Warm-season turfgrass with a C4 photosynthetic pathway grows well between temperatures of $24^{\circ} \mathrm{C}$ and $29^{\circ} \mathrm{C}$ [9]. C. dactylon is more sensitive to cold stress than heat stress $[10,11]$. When mean temperatures decline to $15{ }^{\circ} \mathrm{C}$, the growth of development of $C$. dactylon slows, while leaf senescence occurs at $10^{\circ} \mathrm{C}$ [12]. The response of common Bermuda grass accessions to cold temperatures varies greatly. The varying responses of the morphological structure and function of several differentially expressed proteins in $C$. dactylon to low temperatures have been studied [13]. There is considerable genetic variation in how natural populations of $C$. dactylon tolerate various environmental stresses [10]. As such, this study examines genetic variation in natural populations of Cynodon dactylon (L.) Pers. (common Bermuda grass) with a wide distribution at different temperatures.

Genetic divergence among individuals within a population can lead to population divergence through adaptive selection responding differently to environmental factors. Additionally, populations could converge if similar genetic variants in different populations are selected. Transcriptomics can help identify climatic factors affecting plant traits and performance. As more plant genomes and transcriptomes are sequenced, further exploration of the causes and effects of evolution becomes possible. Transcriptome sequencing has resulted in a better understanding of genetic and genomic diversification in non-model plants [14-17]. It is also a powerful tool for developing useful SNPs throughout the genome [18,19]. Single nucleotide polymorphisms (SNPs) have emerged as a useful molecular markers for analyzing genetic variation within populations [20-22]. The genetic diversity analysis of Opisthopappus Shih populations by single nucleotide polymorphisms (SNP) was performed in order to obtain valuable information about population genetics [23]. The transcriptomes of two wild populations of $C$. dactylon with different directions of stem growth was studied to better understand genetic diversification [24]. There is limited information about the effects of different environments along latitudinal gradients on population structure, based on SNPs obtained via transcriptome sequencing. The genetic differences along latitudinal gradients at different temperatures could be used to predict genetic features of past environments and the ability to adapt to environmental changes in the future. Landscape genetics studies the ability to produce and transmit adaptive genes [25]. Studying genetic diversity and population structures in different environments helps to identify admixture events, which indicate their potential to adapt to new environmental conditions [26,27]. In this study, we obtained SNPs via transcriptome sequencing and analyzed how genetic variation and structure in 16 populations of Bermuda grass from different latitudinal gradients respond to three different levels of temperature, helping us to better understand plant diversity and evolution along latitudinal gradients and providing a molecular genetic basis for the conservation of natural genetic diversity. It will also contribute to efforts to breed increasingly cold-resistant Bermuda grass.

\section{Results}

\subsection{Genetic Variation of 16 Populations of Cynodon along Latitudinal at Different Temperatures}

A total of 20,684,192 high-quality SNPs were selected from the 553,110 unigenes from the C. dactylon samples to further analyze their population genetics. Considerable genetic variation was estimated among populations (Table 1). Nei's diversity index (Nei's) and Shannon's index (I) were computed for each population at different temperatures based on the obtained allele frequencies. Polymorphism information content (PIC) values were calculated using the formula [28] (Equation (1)):

$$
\text { PIC }=1-\sum_{j=1}^{n} p_{i j}^{2}
$$

where $P_{i j}$ is the frequency of $j$ th allele for ith locus and summation extends over $n$ alleles. 
Table 1. Genetic diversity indexes of $C$. dactylon of different population at different temperatures.

\begin{tabular}{|c|c|c|c|c|c|c|c|c|c|c|c|c|c|c|c|}
\hline & \multicolumn{5}{|c|}{$5^{\circ} \mathrm{C}$} & \multicolumn{5}{|c|}{$20^{\circ} \mathrm{C}$} & \multicolumn{5}{|c|}{$35^{\circ} \mathrm{C}$} \\
\hline & Ho & $\mathrm{He}$ & Nei's & I & PIC & Ho & $\mathrm{He}$ & Nei's & I & PIC & Ho & $\mathrm{He}$ & Nei's & I & PIC \\
\hline 1 & 0.914 & 0.479 & 0.574 & 0.670 & 0.362 & 0.893 & 0.475 & 0.570 & 0.666 & 0.360 & 0.911 & 0.478 & 0.574 & 0.670 & 0.362 \\
\hline 2 & 0.700 & 0.418 & 0.501 & 0.604 & 0.326 & 0.702 & 0.416 & 0.499 & 0.602 & 0.324 & 0.730 & 0.432 & 0.519 & 0.620 & 0.335 \\
\hline 3 & 0.673 & 0.410 & 0.492 & 0.596 & 0.321 & 0.779 & 0.448 & 0.537 & 0.637 & 0.344 & 0.788 & 0.445 & 0.534 & 0.634 & 0.343 \\
\hline 4 & 0.726 & 0.427 & 0.512 & 0.614 & 0.331 & 0.713 & 0.425 & 0.510 & 0.612 & 0.330 & 0.699 & 0.423 & 0.508 & 0.611 & 0.329 \\
\hline 5 & 0.687 & 0.416 & 0.499 & 0.602 & 0.325 & 0.700 & 0.416 & 0.499 & 0.602 & 0.325 & 0.676 & 0.410 & 0.492 & 0.596 & 0.321 \\
\hline 6 & 0.801 & 0.450 & 0.540 & 0.640 & 0.346 & 0.750 & 0.442 & 0.530 & 0.631 & 0.341 & 0.769 & 0.445 & 0.534 & 0.634 & 0.342 \\
\hline 7 & 0.780 & 0.448 & 0.537 & 0.637 & 0.344 & 0.835 & 0.459 & 0.551 & 0.649 & 0.351 & 0.791 & 0.446 & 0.535 & 0.635 & 0.343 \\
\hline 8 & 0.791 & 0.448 & 0.538 & 0.638 & 0.345 & 0.816 & 0.456 & 0.548 & 0.647 & 0.350 & 0.840 & 0.461 & 0.553 & 0.651 & 0.352 \\
\hline 9 & 0.783 & 0.447 & 0.537 & 0.636 & 0.344 & 0.771 & 0.445 & 0.534 & 0.634 & 0.343 & 0.714 & 0.421 & 0.505 & 0.607 & 0.327 \\
\hline 10 & 0.837 & 0.458 & 0.549 & 0.648 & 0.350 & 0.915 & 0.480 & 0.640 & 0.672 & 0.364 & 0.771 & 0.446 & 0.535 & 0.635 & 0.343 \\
\hline 11 & 0.784 & 0.447 & 0.537 & 0.636 & 0.344 & 0.709 & 0.432 & 0.518 & 0.620 & 0.335 & 0.776 & 0.444 & 0.533 & 0.633 & 0.342 \\
\hline 12 & 0.683 & 0.414 & 0.497 & 0.600 & 0.324 & 0.726 & 0.430 & 0.516 & 0.618 & 0.334 & 0.691 & 0.425 & 0.510 & 0.613 & 0.331 \\
\hline 14 & 0.815 & 0.455 & 0.546 & 0.645 & 0.348 & 0.831 & 0.458 & 0.550 & 0.648 & 0.350 & 0.865 & 0.467 & 0.560 & 0.657 & 0.355 \\
\hline 15 & 0.683 & 0.414 & 0.496 & 0.600 & 0.323 & 0.618 & 0.398 & 0.478 & 0.583 & 0.314 & 0.653 & 0.406 & 0.487 & 0.591 & 0.319 \\
\hline 16 & 0.820 & 0.449 & 0.539 & 0.638 & 0.345 & 0.711 & 0.423 & 0.508 & 0.610 & 0.329 & 0.695 & 0.425 & 0.510 & 0.612 & 0.330 \\
\hline Overall & 0.543 & 0.353 & 0.357 & 0.526 & 0.280 & 0.528 & 0.349 & 0.353 & 0.521 & 0.277 & 0.539 & 0.356 & 0.360 & 0.529 & 0.282 \\
\hline
\end{tabular}

Overall values were, Nei's $=0.357,0.353,0.360$, Shanon Wiener index $(\mathrm{I})=0.526,0.521,0.529$ and polymorphism information content $(\mathrm{PIC})=0.280,0.277,0.282$ at $5{ }^{\circ} \mathrm{C}, 20^{\circ} \mathrm{C}$ and $35^{\circ} \mathrm{C}$, respectively. Observed heterozygosity (HO) estimates among all populations and expected heterozygosity (HE) were also calculated to indicate genetic diversity varied among populations. Diversity estimates for some populations at high latitude were a little lower than for the others.

\subsection{Phylogenetic Relationship along Latitudinal Gradients at Different Temperatures}

We analyzed the relationships between different populations along latitudinal gradients using SNP data at different temperature levels by constructing three trees for each temperature treatment (Figure 1). The phylogenetic tree at $20^{\circ} \mathrm{C}$ clearly separated the mid-latitude populations (Group 3) from the other populations. Individuals at $5{ }^{\circ} \mathrm{C}$ formed two clades, composed of populations at low latitudes (Group 1 and Group 2) and high latitudes (Group 3 and Group 4). Compared to the tree at $20^{\circ} \mathrm{C}$, individuals from Group 1 and Group 2 clustered with individuals at $5{ }^{\circ} \mathrm{C}$, which indicates there could be genetic variation in low-latitude populations. The phylogenetic tree of individuals at $35^{\circ} \mathrm{C}$ showed almost the same four clades as at $20^{\circ} \mathrm{C}$. However, we also observed inconsistent patterns between these two trees. Some individuals at high latitudes (populations $7,15,16$ ) clustered together, while some individuals from the other populations were clustered at $35^{\circ} \mathrm{C}$. Additionally, under three temperature treatments, population one clustered together with mid-latitude populations (populations 8-10). We observed widespread admixture across different populations of $C$. dactylon, which could be due to the gene introgression of different genetic populations, particularly those that shared similar geographic origins. Individuals at high latitudes evolved earlier than most individuals at low latitudes. No obvious linear trend of genetic similarity was observed among populations from low to high latitudes, suggesting a divergent pattern of evolution in $C$. dactylon along latitudinal boundaries. We also observed frequent introgressive hybridization in $C$. dactylon along latitudinal gradients. 
Group 1: Populations 1-4

Group 2: Populations 5-8

Group 3: Populations 9-12

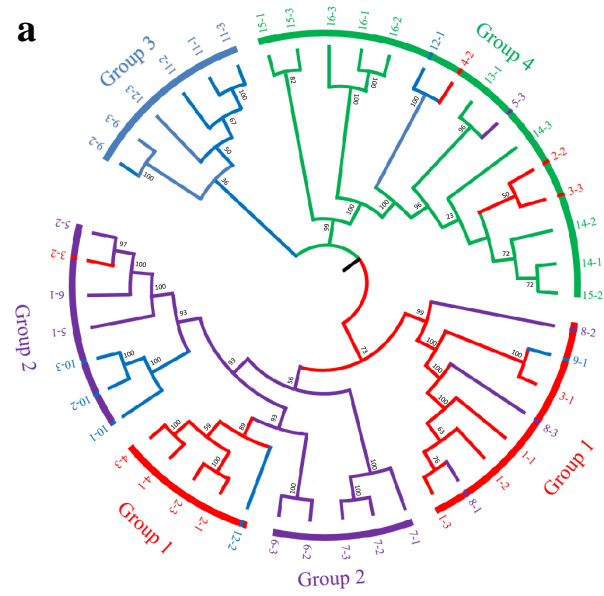

Branch scale: 0.005 ๑

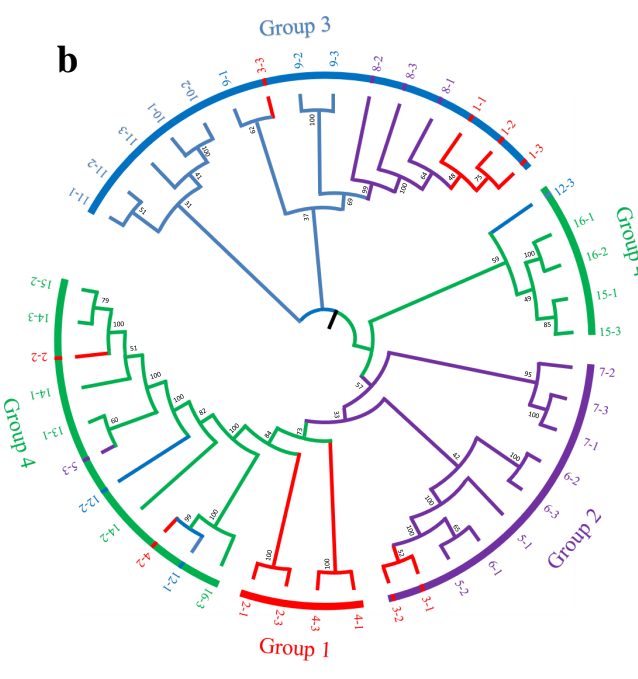

Branch scale: 0.005 -

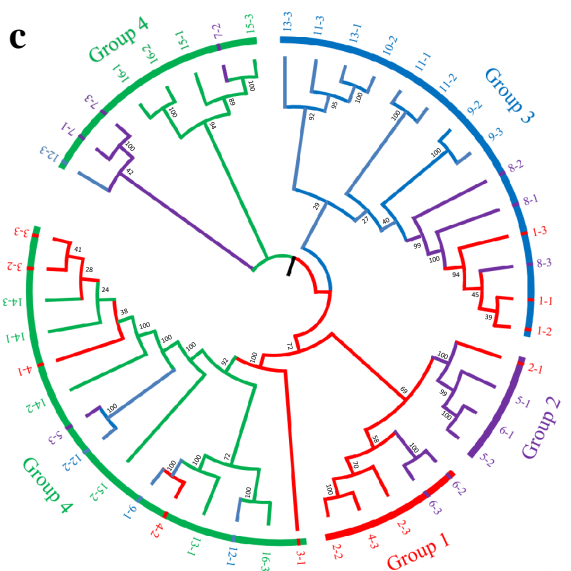

Branch scale: 0.005 u

Figure 1. Maximum-likelihood phylogeny of 16 populations of $C$. dactylon. (a) phylogeny of $C$. dactylon at $5{ }^{\circ} \mathrm{C}$. (b) phylogeny of $C$. dactylon at $20^{\circ} \mathrm{C}$. (c) phylogeny of C. dactylon at $35^{\circ} \mathrm{C}$. Group 1 contains populations 1-4; Group 2 contains populations 5-8; Group 3 contains populations 9-12; Group 4 contains populations 13-16. 


\subsection{Population Genetic Structure}

After additional analysis of molecular variance (AMOVA) analyses, we found that more variation occurred at a temperature of $5{ }^{\circ} \mathrm{C}(\mathrm{SS}=91,708.467)$ and $35^{\circ} \mathrm{C}(\mathrm{SS}=90,139.609)$, compared to $20^{\circ} \mathrm{C}$ $(\mathrm{SS}=57,584.466)$. High genetic differentiation was detected within populations at different temperature levels. Additionally, lower genetic differentiation was observed among populations from all latitudes when grown in low and high temperatures than when grown at $20^{\circ} \mathrm{C}$, whereas relatively low genetic differentiation was observed within populations at $20^{\circ} \mathrm{C}$ (Table 2).

Table 2. Analysis of molecular variance (AMOVA) of C. dactylon of different population at different temperatures.

\begin{tabular}{|c|c|c|c|c|c|c|}
\hline $5^{\circ} \mathrm{C}$ & & & & & & \\
\hline Source of Variation & df & SS & MS & Estimate of Variation & $\%$ & Fixation Index (Fst) \\
\hline Among Populations & 15 & $44,715.134$ & 2981.008933 & 4.11 & $5.56 \%$ & \\
\hline Within Populations & 30 & $46,993.333$ & 1566.444433 & 69.78 & $94.44 \%$ & 0.041 * \\
\hline Total & 45 & $91,708.467$ & & 73.89 & & \\
\hline \multicolumn{7}{|l|}{$20^{\circ} \mathrm{C}$} \\
\hline Source of Variation & df & SS & MS & Estimate of Variation & $\%$ & Fixation Index (Fst) \\
\hline Among Populations & 15 & $28,819.383$ & 1921.2922 & 4.36 & $5.90 \%$ & $0.044 *$ \\
\hline Within populations & 29 & $28,765.083$ & 991.8994138 & 69.5 & $94.10 \%$ & \\
\hline Total & 44 & $57,584.466$ & & 73.86 & & \\
\hline \multicolumn{7}{|l|}{$35^{\circ} \mathrm{C}$} \\
\hline Source of Variation & df & SS & MS & Estimate of Variation & $\%$ & Fixation Index (Fst) \\
\hline Among Populations & 15 & $43,718.942$ & 2914.596133 & 4.16 & $5.70 \%$ & $0.042 *$ \\
\hline Within Populations & 30 & $46,420.667$ & 1547.355567 & 68.85 & $94.30 \%$ & \\
\hline Total & 45 & $90,139.609$ & & 73.01 & & \\
\hline
\end{tabular}

Note: df, degree of freedom, SS, sum of squares, MS, mean of squares; ${ }^{*}$, significant at $5 \%$ level $(p<0.05)$.

SNPs based on the $C$. dactylon transcriptome sequence $(20,684,192$ SNPs) were used to investigate genetic structure at different temperatures using principal component analysis (PCA) (Figure 2). The PC1 accounted for $29.19 \%, 30.80 \%$, and $28.26 \%$ of the variance in SNP data at $5{ }^{\circ} \mathrm{C}, 20^{\circ} \mathrm{C}$, and $35^{\circ} \mathrm{C}$, respectively, while the PC2 accounted for $5.50 \%, 5.94 \%$, and $6.05 \%$ of the variance in SNP data at $5{ }^{\circ} \mathrm{C}, 20^{\circ} \mathrm{C}$, and $35{ }^{\circ} \mathrm{C}$, respectively. The PCA plot of $\mathrm{C}$. dactylon populations at $20^{\circ} \mathrm{C}$ shows that most individuals at low latitudes and middle latitudes were grouped into cluster one, while two populations (number one and eight) were grouped in cluster three. The high-latitude populations grouped in cluster two were clearly separated from the others. The principal component analysis (PCA) (Figure 2) revealed a similar pattern, as indicated by the UPGMA (Unweighted Pair-group Method with Arithmetic Mean) dendrogram. In the PCA plot of C. dactylon populations at $35^{\circ} \mathrm{C}$, on axis one, the 16 populations were divided into two parts: one consisting of cluster two and the other of clusters one and three. On axis two, cluster two consists of high-latitude populations that are divided into cluster two (a) and cluster two (b). However, at axis two, cluster one (a) consists of low-latitude populations that could be separated from cluster one (b) based on the results of PCoA on C. dactylon populations at $5{ }^{\circ} \mathrm{C}$.

The genetic structure coincided with the clustered results of $C$. dactylon $(\mathrm{K})$ from one to 10 . The best $\mathrm{K}$-value along latitudinal gradients for our analysis was estimated as $\mathrm{K}=2, \mathrm{~K}=3$ and $\mathrm{K}=3$ at $5{ }^{\circ} \mathrm{C}, 20^{\circ} \mathrm{C}$, and $35^{\circ} \mathrm{C}$, respectively (Figure 3). In the structure analysis of the $\mathrm{C}$. dactylon populations at three different temperatures, most high-latitude samples differed from the other populations at middle latitudes and low latitudes (Figure 4). When $\mathrm{K}=2$, based on the results of structure on $C$. dactylon populations at $5{ }^{\circ} \mathrm{C}$, most high-latitude samples remained in the yellow cluster. Additionally, most samples at middle latitudes and low latitudes remained in the green cluster. When $\mathrm{K}=3$, most samples at middle latitudes and low latitudes remained in the gray cluster according to the results of structure on $C$. dactylon populations at $20^{\circ} \mathrm{C}$ and $35^{\circ} \mathrm{C}$, while most high-latitude samples remained in the yellow cluster at $20^{\circ} \mathrm{C}$ and $35^{\circ} \mathrm{C}$. Some of these mid-latitude individuals had close evolutionary relationships with low-latitude individuals. Population one was different from low-latitude populations, and grouped 
together with population eight. When $\mathrm{K}=4$, there were four clusters at different temperatures: populations at low-latitude, mid-latitude, high-latitude, population one and eight clustered together.
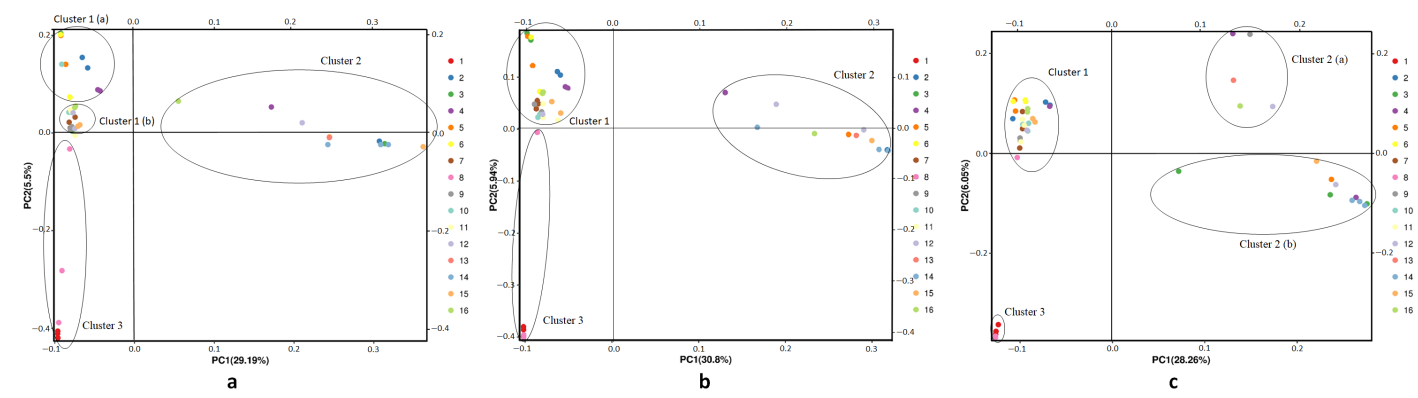

Figure 2. Principal component analysis (PCA) of 16 C. dactylon populations at different temperatures. Different colors indicate different populations. Black circles represent genetic clusters. (a) PCA of C. dactylon at $5{ }^{\circ} \mathrm{C}$. (b) PCA of C. dactylon at $20^{\circ} \mathrm{C}$. (c) PCA of C. dactylon at $35^{\circ} \mathrm{C}$.
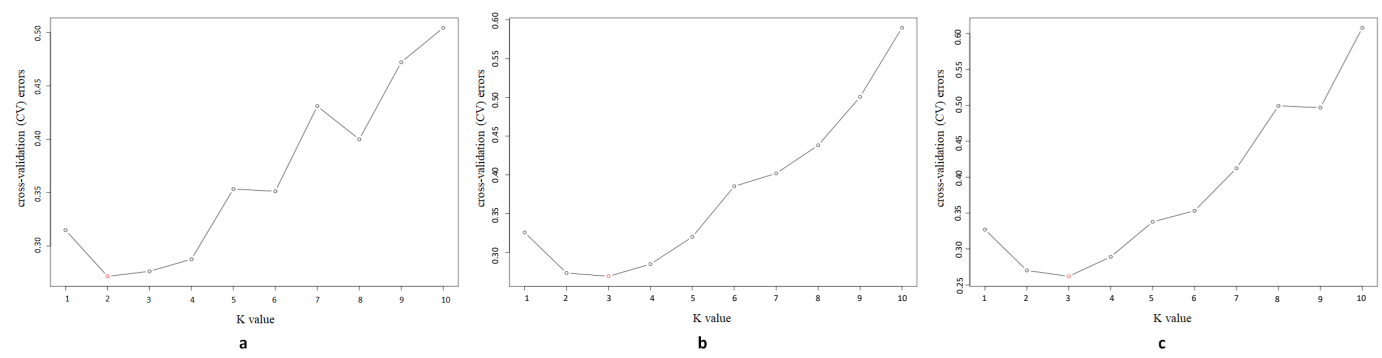

Figure 3. Cross-validation (CV) errors of different $\mathrm{K}$ values $(\mathrm{k}=1-10)$ at different temperatures. Red circles represent $\mathrm{CV}$ errors of best $\mathrm{K}$-value. (a) $\mathrm{CV}$ errors at $5{ }^{\circ} \mathrm{C}$. (b) $\mathrm{CV}$ errors at $20^{\circ} \mathrm{C}$. (c) $\mathrm{CV}$ errors at $35^{\circ} \mathrm{C}$.

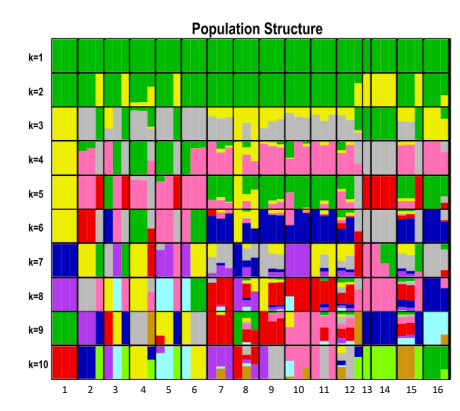

a

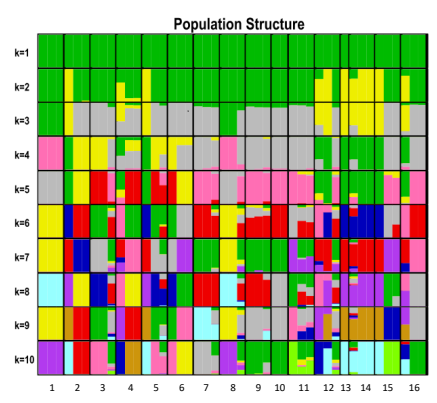

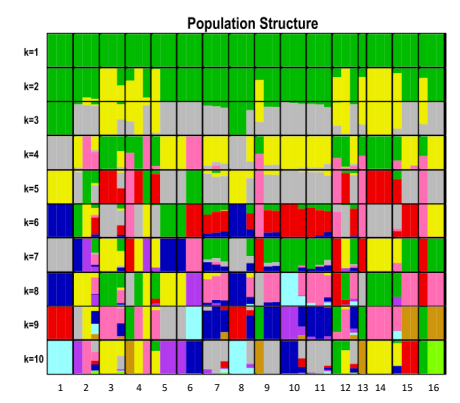

Figure 4. Genetic structure 16 populations of $C$. dactylon along latitudinal gradient at different temperatures. The STRUCTURE ancestry kinship (K) is shown from 1 to 10 . Various colors indicate different genetic clusters. (a) structure of $\mathrm{C}$. dactylon at $5{ }^{\circ} \mathrm{C}$. (b) structure of $\mathrm{C}$. dactylon at $20^{\circ} \mathrm{C}$. (c) structure of C. dactylon at $35^{\circ} \mathrm{C}$.

\section{Discussion}

\subsection{Population Genetic Differentiation and Structure of C. dactylon}

The relationship between local selection and adaptation with climate variables across different geographic locations could be associated with longstanding evolutionary mechanisms. Local selection and genetic drift could shape genetic diversity and differentiation patterns for $C$. dactylon along a latitudinal gradient. Greater intraspecific genetic variation, based on our analysis of molecular variance (AMOVA), could confer a competitive advantage in a changing environment. These results 
agree with the published results of our analysis of the genetic structure using expressed sequence tag-derived simple sequence repeats (EST-SSR) [29]. Higher environmental heterogeneity could favor higher tolerance of environmental factors and a broader range of acclimation responses [30,31]. This could explain the genetically diverse populations we identified when analyzing genetic structures. Populations of $C$. dactylon at high latitudes differed from other populations at middle latitudes and lower latitudes based on an analysis of their genetic structure. The results of both the genetic structure analysis and the PCA analysis corresponded to growth habits [32-34]. Migration among different populations was assumed in our structure analyses, while gene flow could have caused populations at different latitudes to adapt to similar conditions, which has been well-researched [29]. Proposed adaptive introgression could allow for adaptation and establishment in different environmental conditions [35]. Some of these individuals were admixed, which indicates that hybridization and introgression occurred during the evolutionary process.

Additionally, C. dactylon at low latitudes could emerge directly from most individuals at high latitudes, according to the results of our phylogenetic analysis at different temperatures. Most individuals at low latitudes are descendants of populations located at high latitudes, which could be due to the evolution of genetic diversity along latitudinal gradients. Biogeographic studies have demonstrated a southward migration towards warmer regions [36,37]. Our results also indicate that phylogenetic clustering at high latitudes, along with the phylogenetic structure, tended to disperse individuals at low latitudes, due to favorable temperatures. The evolution of plants, along with geological events, could help understand evolutionary history. Climatic fluctuations and numerous, complex ecological niches could promote north-south exchanges [38]. Phylogeographic studies and additional investigation into climatic and environmental changes provide a new perspective on the history of population changes.

\subsection{Analysis of C. dactylon Landscape Genetics}

These results demonstrate the importance of identifying the geographical source of a sample during an experiment, as well as the need to study different temperature levels in order to fully understand how genetic variation affects the adaptive abilities of C. dactylon. Genetic resources of wild plant species are helpful for plant breeding [39,40], so the germplasm from wild Bermuda grass collected from all over the world is significant for the conservation of natural genetic diversity. The rapid development of high-throughput molecular methods (such as SNPs) used in this study has allowed us to better understand the differences and evolutionary patterns of $C$. dactylon. Individuals at low latitudes have likely adapted to relatively higher temperatures, while low temperatures affected the genetic variation of populations at low latitudes. Across evolutionary time, individuals typically appeared at low latitudes subsequent to appearing at high latitudes, indicating that $C$. dactylon could have evolved from northern latitudes to southern latitudes. An analysis of genetic structure determined that populations of $C$. dactylon at high latitudes differed from populations at middle latitudes and low latitudes. Understanding genetic variation across geographic boundaries provides a deeper understanding of the study of evolutionary patterns. Our study suggests a valuable pattern of population genetics at different latitudes for the genomic evolution of $C$. dactylon. Additionally, some populations and individuals can be used to breed strains that are highly resistant to cold temperatures. This analysis will provide the foundation for future structural and comparative genomic studies of $C$. dactylon, and will also provide additional insight into the evolutionary phenomenon of landscape genetics.

\subsection{Adaptation of Genetic Variation along Latitudinal Gradients to Different Temperatures}

Genetic variation among populations can occur as an adaptation to a wide range of climatic conditions, including temperature [41,42]. Inverse relationships between latitude and diversification rate have been observed; temperature, in particular, has the highest impact on the diversification rate of plants $[43,44]$. In our study, higher levels of genetic differentiation within populations were observed at 
$5{ }^{\circ} \mathrm{C}$ than at $20^{\circ} \mathrm{C}$. Additionally, samples from low latitudes were clearly separated from samples from high-latitudes at $5{ }^{\circ} \mathrm{C}$. Temperature is one of the primary drivers of community change in plants [45]. This may indicate that low temperatures affected the genetic variation of populations at low latitudes, which had low resistance to cold temperatures. Guangzhou (population two), Yingde (population three), Renhua (population four), Guidong (population five), Youxian (population six), and Liuyang (population seven) are all located at low latitudes and have high annual average temperatures. Low temperatures limit the distribution and development of most plant species [13]. For example, southern lineages of scallops located at higher latitudes live in warmer offshore waters because they have adapted to high temperatures [46]. Genetic variation should allow populations of A. millepora to adapt to gradual warming, while novel genetic mutations could induce further adaptations [47]. High temperatures could affect populations from Cixian (population 16) and Huixian (population 15), which are located at relatively high latitudes. Higher temperatures are correlated with high rates of genetic mutation, based on the evolutionary speed hypothesis [48]. Additionally, populations from Liuyang (population 7) could be affected by both low and high temperatures. Populations at different latitudes could adapt differently to different temperatures due to genetic diversity among populations. Local adaptation to different temperature conditions promotes evolutionary diversification [49]. Increased heterozygosity of polyploids at low and high latitudes helps to adapt to different environmental conditions [50]. To make the results more comprehensive, we identified differentially expressed genes (DEGs) that were highly correlated with the diversification of $C$. dactylon for functional analysis associated with temperature (unpublished paper).

\section{Material and Methods}

\subsection{Plant Material and Experimental Design}

All 137 samples of Cynodon dactylon (L.) Pers. were collected from 16 geographic sites across China, ranging from $22^{\circ} 35^{\prime} \mathrm{N}$ to $36^{\circ} 18^{\prime} \mathrm{N}$ (Figure 5; Table S1). They were then all planted in the experimental farm of Yangzhou University, Yangzhou, China, in 2018. We sampled 48 individuals (with random three individuals from 20 individuals for each population) and planted them at three different temperatures: $5{ }^{\circ} \mathrm{C}, 20^{\circ} \mathrm{C}$ and $35^{\circ} \mathrm{C}$ for 2 months. The growing conditions were the same within the three climatic chambers: the humidity was $60 \%$, the photoperiod was $12 \mathrm{~h} \mathrm{~d}^{-1}$, and the luminosity was $600 \mu \mathrm{mol}$ photon $\mathrm{m}^{-2} \mathrm{~s}^{-1}$. Field experiments were based on a randomized complete block design within each climatic chamber. Forty-eight individuals of $C$. dactylon from the 16 populations were cultivated on a plot, while the distance between the plants was $10 \mathrm{~cm}$ and the distance between rows was $20 \mathrm{~cm}$. The leaves of each plant in each growing chamber were sampled and immediately flash frozen in liquid nitrogen for RNA extraction.

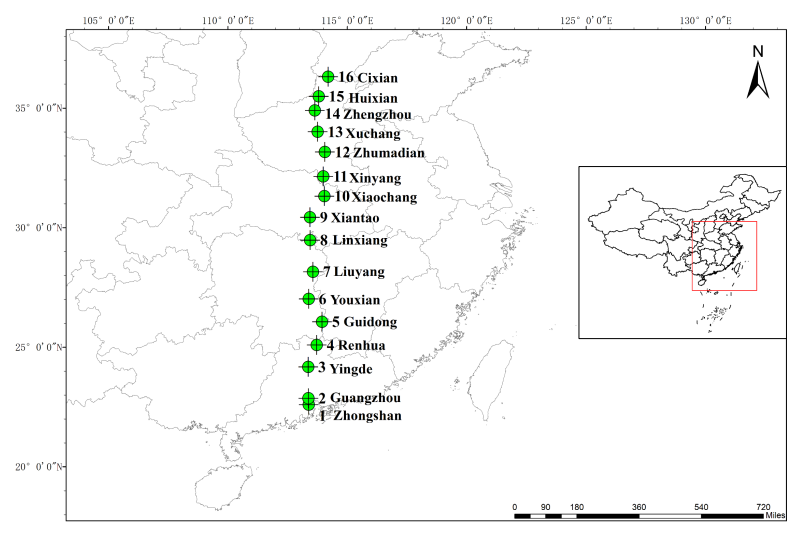

Figure 5. Distribution of $C$. dactylon populations in southeastern China. The green dot represents the sampling sites of transcriptome sequencing. 


\subsection{RNA Extraction and Sequencing}

RNA was extracted using the Plant RNA Kit (OMEGA, Norcross, GA, USA) according to the manufacturer's instructions. The RNA concentration and quality were determined using a NanoDrop spectrophotometer (Thermo Scientific, Wilmington, DE, USA) and an Agilent Bioanalyzer (Agilent, Santa Clara, CA, USA). High-quality mRNA obtained from the total RNA sample and oligo dT primer was then used for reverse transcription (RT) to generate CDNA, using a cDNA synthesis kit (Clontech Laboratories, Mountain View, CA, USA). All of the products of PCR reactions following RT were purified using AMPure PB beads (Pacific Biosciences, Menlo Park, CA, USA), while the DNA fragments were selected using the BluePippin System. The products were then quantified using an Agilent 2100 Bioanalyzer (Agilent Technologies, Inc., Santa Clara, CA, USA), while the sequencing libraries were prepared using Illumina TruSeq kits. Paired-end sequencing with an insert size of $\sim 150$ bp was performed using the Illumina HiSeq 2000 platform. Clean reads were obtained using a stringent filtering process and an adapter.

\subsection{Detection of SNP Population and Data Analysis}

SNPs for each individual were analyzed using the GATK (The Genome Analysis Toolkit, Broad Institute) software [51]. From transcriptome sequence of non-model plant, we obtained high-quality SNPs (Table S2) and excluded SNP calling errors. We analyzed the values of genetic variation among and within populations using the AMOVA analysis, while the significance was tested using 999 permutations generated by the ARLEQUIN software [52]. We also used principal component analysis (PCA) using the EIGENSOFT software to quantify the distribution of genetic variation at different latitudes [53].

\subsection{Population Structure and Phylogenetic Tree}

The population structure at different latitudes was analyzed using the ADMIXTURE software, with a burn-in period of 10,000 generations and 50,000 iterations [54]. We tested populations (K) from 1 to 10 with default convergence criterion, while the best K-value was selected based on the lowest value of cross-validation errors (CV). Individuals along a latitudinal gradient were separated into four groups with four populations of one group by latitude from south to north. A tree illustrating the genetic relationship among the four groups at different temperatures was generated based on SNP data using MEGAX (MEGA-CC) and the Kimura 2-parameter model with 1000 bootstrap replicates.

Supplementary Materials: The following are available online at http://www.mdpi.com/2223-7747/9/12/1778/s1, Table S1: Geographical distribution of 16 C. dactylon sampled populations. Table S2: SNP numbers of C. dactylon among latitudinal gradient at different temperature.

Author Contributions: J.-X.Z., M.-H.C., Y.S., J.Q. and M.-L.H. performed the experiments. Y.-X.G. provided these samples. J.-X.Z. analyzed the data and wrote the manuscript. J.-X.Z., L.G., C.-J.Z. and X.-B.Y. edited the manuscript. All authors have read and agreed to the published version of the manuscript.

Funding: This research received no external funding.

Conflicts of Interest: The authors declare that the research was conducted in the absence of any commercial or financial relationships that could be constructed as a potential conflict of interest.

\section{References}

1. Avis, J.D.; Taliaferro, C.M.; Holbert, D. Genotype $\times$ interaction study of bermuda grass yields in Oklahoma. Proc. Okla. Acad. Sci. 1980, 60, 69-74.

2. Salehi, M.; Salehi, H.; Niazi, A.; Ghobadi, C. Convergence of goals: Phylogenetical, morphological, and physiological characterization of tolerance to drought stress in tall fescue (Festuca arundinacea Schreb.). Mol. Biotechnol. 2013, 56, 248-257. [CrossRef] [PubMed]

3. Luo, N.; Liu, J.; Yu, X.; Jiang, Y. Natural variation of drought response in Brachypodium distachyon. Physiol. Plant. 2011, 141, 19-29. [CrossRef] [PubMed] 
4. Fournier-Level, A.; Korte, A.; Cooper, M.D.; Nordborg, M.; Schmitt, J.; Wilczek, A.M. A map of local adaptation in arabidopsis thaliana. Science 2011, 334, 86-89. [CrossRef] [PubMed]

5. Ciais, P.; Reichstein, M.; Viovy, N.; Granier, A.; Ogée, J.; Allard, V.; Aubinet, M.; Buchmann, N.; Bernhofer, C.; Carrara, A.; et al. Europe-wide reduction in primary productivity caused by the heat and drought in 2003. Nature 2005, 437, 529-533. [CrossRef] [PubMed]

6. Shi, H.; Ye, T.; Chan, Z. Exogenous application of hydrogen sulfide donor sodium hydrosulfide enhanced multiple abiotic stress tolerance in bermuda grass (Cynodon dactylon (L). Pers.). Plant Physiol. Biochem. 2013, 71, 226-234. [CrossRef]

7. Cahill, A.E.; Aiello-Lammens, M.E.; Fisher-Reid, M.C.; Hua, X.; Fisher-Reid, M.C.; Karanewsky, C.J.; Hae Yeong Ryu, C.J.; Sbeglia, G.C.; Spagnolo, F.; Waldron, J.B.; et al. How does climate change cause extinction? Proc. R. Soc. B Biol. Sci. 2013, 280, 20121890. [CrossRef]

8. Merriam, C.H. Laws of temperature and control of the geographic distribution of terrestrial animals and plants. Natl. Geogr. Mag. 1894, 6, 229-238.

9. Beard, J.B. Turfgrass: Science and Culture; Prentice-Hall, Inc.: Englewood Cliffs, NJ, USA, 1973; 672p.

10. Anderson, J.; Taliaferro, C.; Martin, D. Freeze tolerance of bermuda grasses. Crop Sci. 2002, 42, 975-977.

11. Munshaw, G.C.; Ervin, E.H.; Beasley, J.S.; Shang, C.; Zhang, X.; Parrish, D.J. Effects of late-season ethephon applications on cold tolerance parameters of four bermuda grass cultivars. Crop Sci. 2011, 50, 1022-1029. [CrossRef]

12. Akbari, M.; Salehi, H.; Niazi, A. Evaluation of Diversity Based on Morphological Variabilities and ISSR Molecular Markers in Iranian Cynodon dactylon (L.) Pers. Accessions to Select and Introduce Cold-Tolerant Genotypes. Mol. Biotechnol. 2018, 60, 259-270. [CrossRef]

13. Shi, Y.; Ding, Y.; Yang, S. Cold signal transduction and its interplay with phytohormones during cold acclimation. Plant Cell Physiol. 2014, 56, 7-15. [CrossRef] [PubMed]

14. Lee, E.K.; Cibrian-Jaramillo, A.; Kolokotronis, S.O.; Katari, M.S.; Stamatakis, A.; Ott, M.; Chiu, J.C.; Little, D.P.; Stevenson, D.W.; Richard McCombie, W.; et al. A functional phylogenomic view of the seed plants. PLoS Genet. 2011, 7, e1002411. [CrossRef] [PubMed]

15. Dohm, J.C.; Minoche, A.E.; Holtgrawe, D.; Capella-Gutiérrez, S.; Zakrzewski, F.; Tafer, H.; Rupp, O.; Sörensen, T.R.; Stracke, R.; Reinhardt, R.; et al. The genome of the recently domesticated crop plant sugar beet (Beta vulgaris). Nature 2014, 505, 546-549. [CrossRef] [PubMed]

16. Sveinsson, S.; McDill, J.; Wong, G.K.; Li, J.; Li, X.; Deyholos, M.K.; Cronk, Q.C. Phylogenetic pinpointing of a paleopolyploidy event within the flax genus (Linum) using transcriptomics. Ann. Bot. 2014, 113, 753-761. [CrossRef]

17. Wickett, N.J.; Mirarab, S.; Nguyen, N.; Warnow, T.; Carpenter, E.; Matasci, N.; Ayyampalayam, S.; Barker, M.S.; Burleigh, J.G.; Gitzendanner, M.A.; et al. Phylotranscriptomic analysis of the origin and early diversification of land plants. Proc. Natl. Acad. Sci. USA 2014, 111, E4859-E4868. [CrossRef]

18. Mckain, M.R.; Wickett, N.J.; Zhang, Y.; Ayyampalayam, S.; Mccombie, W.R.; Chase, M.W.; Pires, J.C.; Depamphilis, C.W.; Leebensmack, J. Phylogenomic analysis of transcriptome data elucidates co-occurrence of a paleopolyploid event and the origin of bimodal karyotypes in Agavoideae (Asparagaceae). Am. J. Bot. 2012, 99, 397-406. [CrossRef]

19. Wen, J.; Xiong, Z.; Nie, Z.L.; Mao, L.; Zhu, Y.; Kan, X.Z.; Ickert-Bond, S.M.; Gerrath, J.; Zimmer, E.A.; Fang, X.D. Transcriptome sequences resolve deep relationships of the grape family. PLoS ONE 2013, 8, e74394. [CrossRef]

20. Brumfield, R.T.; Beerli, P.; Nickerson, D.A.; Edwards, S.V. The utility of single nucleotide polymorphisms in inferences of population history. Trends. Ecol. Evol. 2003, 18, 249-256. [CrossRef]

21. Garvin, M.R.; Saitoh, K.; Gharrett, A.J. Application of single nucleotide polymorphisms to non-model species: A technical review. Mol. Ecol. Res. 2010, 10, 915-934. [CrossRef]

22. Helyar, S.J.; Hemmer-Hansen, J.; Bekkevold, D.; Taylor, M.I.; Nielsen, E.E. Application of snps for population genetics of nonmodel organisms: New opportunities and challenges. Mol. Ecol. Res. 2011, 11, 123-136. [CrossRef] [PubMed]

23. Chai, M.; Wang, S.; He, J.; Chen, W. De novo assembly and transcriptome characterization of Opisthopappus (Asteraceae) for population differentiation and adaption. Front. Genet. 2018, 9, 371. [CrossRef] [PubMed] 
24. Zhang, B.; Xiao, X.L.; Zong, J.Q.; Chen, J.B.; Li, J.J.; Guo, H.L. Comparative transcriptome analysis provides new insights into erect and prostrate growth in bermuda grass (Cynodon dactylon L.). Plant Physiol. Biochem. 2017, 2017, 31-37. [CrossRef] [PubMed]

25. Jordan, R.; Hoffmann, A.A.; Dillon, S.K.; Prober, S.M. Evidence of genomic adaptation to climate in Eucalyptus microcarpa: Implications for adaptive potential to projected climate change. Mol. Ecol. 2017, 26, 6002-6020. [CrossRef] [PubMed]

26. Sakai, A.K.; Allendorf, F.W.; Holt, J.S.; Lodge, D.M.; Molofsky, J.; Baughman, S.; Cabin, R.J.; Cohen, J.E.; Ellstrand, N.C.; Mccauley, D.E.; et al. The population biology of invasive species. Annu. Rev. Ecol. Evol. Syst. 2001, 32, 305-332. [CrossRef]

27. Lee, C.E. Evolutionary genetics of invasive species. Trends. Ecol. Evol. 2002, 17, 386-391. [CrossRef]

28. Liu, P.; Que, Y.; Pan, Y.B. Highly polymorphic microsatellite DNA markers for sugarcane germplasm evaluation and variety identity testing. Sugar Tech. 2011, 13, 129-136. [CrossRef]

29. Zhang, J.X.; Wang, M.L.; Guo, Z.P.; Guan, Y.Z.; Liu, J.Y.; Yan, X.B.; Guo, Y.X. Genetic Diversity and Population Structure of Bermuda grass [Cynodon dactylon (L.) Pers.] along Latitudinal Gradients and the Relationship with Polyploidy Level. Diversity 2019, 11, 135. [CrossRef]

30. Janzen, D.H. Why mountain passes are higher in tropics. Am. Nat. 1967, 101, 233-249. [CrossRef]

31. Ghalambor, C.K.; Huey, R.B.; Martin, P.R.; Tewksbury, J.J.; Wang, G. Are mountain passes higher in the tropics? Janzen's hypothesis revisited. Integr. Comp. Biol. 2006, 46, 5-17. [CrossRef]

32. Gazave, E.; Tassone, E.E.; Ilut, D.C.; Wingerson, M. Population genomic analysis reveals differential evolutionary histories and patterns of diversity across subgenomes and subpopulations of Brassica napus $\mathrm{L}$. Front. Plant Sci. 2016, 7, 525. [CrossRef] [PubMed]

33. Becker, H.C.; Engqvist, G.M.; Karlsson, B. Comparison of rapeseed cultivars and resynthesized lines based on allozyme and RFLP markers. Theor. Appl. Genet. 1995, 91, 62-67. [CrossRef] [PubMed]

34. Wu, J.; Li, F.; Xu, K.; Gao, G.; Chen, B.; Yan, G.; Wang, N.; Qiao, J.; Li, J.; Li, H.; et al. Assessing and broadening genetic diversity of a rapeseed germplasm collection. Breed. Sci. 2014, 64, 321-330. [CrossRef] [PubMed]

35. Hufford, M.B.; Lubinksy, P.; Pyhäjärvi, T.; Devengenzo, M.T.; Ellstrand, N.C.; Ross-Ibarra, J. The genomic signature of crop-wild introgression in maize. PLoS Genet. 2013, 9, e1003477. [CrossRef]

36. Ebersbach, J.; Muellner-Riehl, A.N.; Michalak, I.; Tkach, N.; Hoffmann, M.H.; Roeser, M.; Sun, H.; Favre, A. In and out of the Qinghai-Tibet Plateau: Divergence time estimation and historical biogeography of the large arctic-alpine genus Saxifraga, L. J. Biogeogr. 2017, 44, 900-910. [CrossRef]

37. Kim, C.; Deng, T.; Wen, J.; Nie, Z.L.; Sun, H. Systematics, biogeography, and character evolution of deutzia (hydrangeaceae) inferred from nuclear and chloroplast dna sequences. Mol. Phylogenetics Evol. 2015, 87, 91-104. [CrossRef]

38. Sun, H.; Zhang, J.; Deng, T.; Boufford, D.E. Origins and evolution of plant diversity in the Hengduan Mountains, China. Plant Divers. 2017, 39, 161. [CrossRef]

39. Hajjar, R.; Hodgkin, T. The use of wild relatives in crop improvement: A survey of developments over the last 20 years. Euphytica 2007, 156, 1-13. [CrossRef]

40. Kearns, R.; Zhou, Y.; Fukai, S.; Ye, C.; Loch, D.; Godwin, I.D.; Holton, T.; Innes, D.; Stirling, H.; Cao, N.; et al. Eco-turf: Water use efcient turfgrasses from Australian biodiversity. Acta Hortic. 2009, 829, $113-118$. [CrossRef]

41. Durka, W.; Michalski, S.G.; Berendzen, K.W.; Bossdorf, O.; Bucharova, A.; Hermann, J.M.; Hölzel, N.; Kollmann, J. Genetic differentiation within multiple common grassland plants supports seed transfer zones for ecological restoration. J. Appl. Ecol. 2017, 54, 116-126. [CrossRef]

42. Michalski, S.G.; Durka, W.; Jentsch, A.; Kreyling, J.; Pompe, S.; Schweiger, O.; Willner, E.; Beierkuhnlein, C. Evidence for genetic differentiation and divergent selection in an autotetraploid forage grass (Arrhenatherum elatius). Theor. Appl. Genet. 2010, 120, 1151-1162. [CrossRef] [PubMed]

43. Jansson, R.; Davies, T.J. Global variation in diversification rates of flowering plants: Energy vs. climate change. Ecol. Lett. 2008, 11, 173-183. [CrossRef] [PubMed]

44. Svenning, J.C.; Borchsenius, F.; Bjorholm, S.; Balslev, H. High tropical net diversification drives the New World latitudinal gradient in palm (Arecaceae) species richness. J. Biogeogr. 2008, 35, 394-406. [CrossRef]

45. McFadden, I.R.; Sandel, B.; Tsirogiannis, C.; Moruetaholme, N.; Svenning, J.; Enquist, B.J.; Kraft, N.J.B. Temperature shapes opposing latitudinal gradients of plant taxonomic and phylogenetic $\beta$ diversity. Ecol. Lett. 2019, 22, 1126-1135. [CrossRef] 
46. Lehnert, S.J.; DiBacco, C.; Van Wyngaarden, M.; Jeffery, N.W.; Ben Lowen, J.; Sylvester, E.V.A.; Wringe, B.F.; Stanley, R.R.E.; Hamilton, L.C.; Bradbury, I.R. Fine-scale temperature-associated genetic structure between inshore and offshore populations of sea scallop (Placopecten magellanicus). Heredity 2019, 122, 69. [CrossRef] [PubMed]

47. Matz, M.V.; Treml, E.A.; Aglyamova, G.V.; Bay, L.K. Potential and limits for rapid genetic adaptation to warming in a Great Barrier Reef coral. PLoS Genet. 2018, 14, e1007220. [CrossRef] [PubMed]

48. Rohde, K. Latitudinal gradients in species diversity: The search for the primary cause. Oikos 1992, 65, 514-527. [CrossRef]

49. Jorde, P.E.; SoVik, G.; Westgaard, J.I.; Albretsen, J.; André, C.; Hvingel, C.; Johansen, T.; Sandvik, A.D.; Kingsley, M.; Jørstadet, K.E. Genetically distinct populations of northern shrimp, Pandalus borealis, in the North Atlantic: Adaptation to different temperatures as an isolation factor. Mol. Ecol. 2015, 24, 1742-1757. [CrossRef] [PubMed]

50. Lowry, E.; Lester, S.E. The biogeography of plant reproduction: Potential determinants of species' range sizes. J. Biogeogr. 2006, 33, 1975-1982. [CrossRef]

51. McKenna, A.; Hanna, M.; Banks, E.; Sivachenko, A.; Cibulskis, K.; Kernytsky, A.M.; Garimella, K.; Altshuler, D.; Gabriel, S.; Daly, M.J.; et al. The Genome Analysis Toolkit: A MapReduce framework for analyzing next-generation DNA sequencing data. Genome Res. Ital. 2010, 20, 1297-1303. [CrossRef]

52. Excoffier, L.; Laval, G.; Schneider, S. Arlequinversion3.0: Anintegrated software package for population genetics data analysis. Evol. Bioinform. 2005, 1, 47-50. [CrossRef]

53. Price, A.L.; Patterson, N.J.; Plenge, R.M.; Weinblatt, M.E.; Reich, D. Principal components analysis corrects for stratification in genome-wide association studies. Nat. Genet. 2006, 38, 904-909. [CrossRef] [PubMed]

54. Alexander, D.H.; Novembre, J.; Lange, K. Fast model-based estimation of ancestry in unrelated individuals. Genome Res. 2009, 19, 1655-1664. [CrossRef] [PubMed]

Publisher's Note: MDPI stays neutral with regard to jurisdictional claims in published maps and institutional affiliations.

(C) 2020 by the authors. Licensee MDPI, Basel, Switzerland. This article is an open access article distributed under the terms and conditions of the Creative Commons Attribution (CC BY) license (http://creativecommons.org/licenses/by/4.0/). 